\title{
I - Editorial \\ O Supremo na política: a construção da supremacia judicial no Brasil
}

Diego Werneck Arguelhes*

O Supremo Tribunal Federal está mudando. Compare-o com o tribunal que, no início dos anos 1990, recebeu do constituinte a delicada tarefa de dar sentido concreto aos novos e ambiciosos dispositivos constitucionais de 1988. Da abrangência dos temas que o Supremo decide ao tipo de argumentos que usa, passando pelo alcance das decisões e pela identidade institucional que expressa nas manifestações públicas de seus ministros, parece difícil imaginar mudança mais completa. O cenário atual foi recentemente descrito como "supremocracia" - um termo cujo emprego não teria sido levado a sério há pouco menos de uma década (Vieira, 2008). A cautela política deu lugar à ampla exploração de poderes previstos na Constituição - tanto em inovações recentes, como a súmula vinculante e a repercussão geral, quanto por instrumentos já constantes do texto original, mas que haviam sido jurisprudencialmente adormecidos pelo próprio tribunal nos primeiros anos após a transição, como o mandado de injunção. Ainda que não tenha faltado polêmica sobre o caráter positivo ou negativo do fenômeno, pelo menos quanto ao diagnóstico parece haver consenso: o STF passou a cumprir um papel político central.

\footnotetext{
* Editorialista convidado. Professor de direito constitucional da FGV Direito Rio.
} 
Entretanto, a imagem de uma reviravolta completa - de um deliberado salto da timidez à ousadia - pode ser enganosa. Se, com o cada vez mais frequente rótulo de "ativismo", o que se quer é apenas criticar o STF por ter repentinamente tomado um poder que não seria seu, contra a vontade dos poderes eleitos, corre-se o risco de ignorar os aspectos mais interessantes do processo de expansão do poder judicial no Brasil. Perdemos de vista tanto o que esse processo tem em comum com fenômenos globais, perceptíveis em diversos outros países, como o que ele tem de restrito a um conjunto menor de nações - ou até mesmo no que ele tem de possivelmente único, exclusivo do caso Brasileiro.

\section{II}

Estudos de caso sobre a expansão do poder de cortes supremas e tribunais constitucionais ao redor do mundo têm enfatizado que esse tipo de processo requer condições políticas favoráveis para se desencadear e se manter. ${ }^{1}$ Em um regime de separação de poderes, essas instituições judiciais atípicas necessariamente decidem em interação com os outros poderes políticos. ${ }^{2}$ No mínimo, dependem de comportamentos desses outros agentes no sentido de obedecer às suas decisões, que não podem fazer cumprir por conta própria. Mas, dependendo do desenho institucional do país, os pontos de interação entre os três poderes podem ir muito além da simples e direta escolha pela obediência ou não às decisões judiciais. No Brasil, por exemplo, o presidente e o Senado preenchem em ação conjunta as vagas no STF. São também os outros dois poderes que legislam e alteram a Constituição, dialogando assim com interpretações passadas do STF com as quais estejam em desacordo - ainda que, no caso do Brasil, o STF entenda que tem a última palavra sobre a constitucionalidade material das próprias emendas, um exemplo de competência raramente encontrada no direito comparado e que aumenta bastante o poder da instituição. Foram também sucessivos presidentes, deputados e senadores que, de 1988 para cá, alimentaram o poder do Supremo por recorrerem a ele. A cada ADIn proposta após serem derrotados no Congresso, partidos e parlamentares da oposição - quem quer que seja a oposição da vez - confirmam e aumentam a autoridade do STF. ${ }^{3}$

\footnotetext{
${ }^{1}$ Para análises de processos de expansão do poder judicial que enfatizam as dinâmicas políticas que permitem essa transformação, ver Hirschl (2004) e Ginsburg (2003).

${ }^{2}$ Para um exemplo de "modelo estratégico" de comportamento judicial em um regime de separação de poderes, ver Epstein e Knight (1997).

${ }_{3}^{3}$ Este parece ser um padrão muito comum em diversos outros países (ver Sweet, 2000). Para uma influente análise da presença dos partidos políticos no sistema brasileiro de controle concentrado de constitucionalidade ao longo dos anos 1990, ver o trabalho pioneiro de Vianna, Carvalho, Cunha e Burgos (1999).
} 
Se o texto constitucional - que consagra o STF como "guardião da Constituição" - fosse suficiente para explicar, justificar e alimentar o protagonismo do Supremo, o natural seria que tivéssemos acabado de celebrar 20 anos de ativismo. Não é o caso. O fato de que a predominância do Supremo é um fenômeno relativamente recente, ainda que o papel formal de "guardião" date de 1988, já mostra que a Constituição é variável insuficiente. As respostas devem ser procuradas na interação do STF com a política e, mais concretamente, com os políticos. A observação do que ocorre em outros países sugere que não há "supremocracia" que não tenha sido aqui e ali aceita - ou até incentivada - pelos outros dois poderes, ainda que, hoje, seus atuais representantes possam se ver genuinamente frustrados por decisões do tribunal. Não é apenas a oposição derrotada que tem incentivos para convidar o STF a dar a última palavra. Em cenários de impasses legislativos, dentro de certas condições, mesmo maiorias eventuais podem ter incentivos para obter, pelos votos dos ministros do Supremo, decisões que não conseguem aprovar pelas vias legislativas. Mais ainda, o STF também pode ser útil aos poderes eleitos ao puxar para si temas que eles não querem tratar devido ao seu alto custo eleitoral. Apenas para citar um exemplo recente, será que o Congresso Nacional tem interesse em tratar agora de um tema politicamente delicado como o aborto de fetos com anencefalia? O mesmo vale para várias das súmulas vinculantes. O Congresso pode formalmente afastá-las por meio de legislação ordinária, mas com que frequência isso tem acontecido? Há certos temas cuja "usurpação" pelo Supremo pode representar ganhos políticos para o Congresso. O paradoxo é apenas aparente.

É certo que nem toda interação entre esses dois poderes pode ser explicada como estratégia racional por parte do Congresso. É sempre difícil antecipar estrategicamente o próximo passo de um ator como o Supremo - uma instituição que, uma vez que lhe passem a palavra, pode reescrever os próprios limites da sua competência sob a generosa justificativa da interpretação constitucional. Mas é igualmente certo que a desenvoltura do STF de hoje não pode ser compreendida só a partir do desenho institucional original, sem que se leve em conta o comportamento subsequente dos atores políticos.

Assim, um provável elemento em comum entre o caso brasileiro e outros processos similares de expansão do poder judicial ao redor do mundo está no fato de que o ativismo do Supremo de hoje é politicamente construído. Em diversos momentos do seu processo de formação, dependeu de comportamentos políticos favoráveis - condições que, em última instância, não podem ser criadas por decisão judicial. É necessário investigar como e por que o crescimento da autoridade do tribunal pode ter sido incentivado por sucessivas presidências e legislaturas. Esse cenário traz implicações e oportunidades para a pesquisa em direito comprometi- 
da com a construção das instituições nacionais. É preciso desvelar os mecanismos institucionais e informais pelos quais os caminhos do STF se cruzam - às vezes bloqueando, às vezes sendo bloqueados, às vezes cooperando - com os caminhos do Legislativo e do Executivo. ${ }^{4}$ É igualmente necessário investigar em que condições políticas e por quais mecanismos institucionais o poder do STF pode parar de expandir ou até mesmo voltar a se retrair - variações ao longo do tempo que já foram identificadas em outros países. ${ }^{5}$

Apesar de sua urgência, essas questões não são enfrentadas no discurso doutrinário e judicial global - que, com poucas exceções, concentra-se uniforme e cegamente em uma defesa da supremacia judicial como se esta fosse corolário natural de compromissos com democracia e proteção a direitos fundamentais. ${ }^{6}$ Segundo esse discurso, a consolidação em todo o mundo dos tribunais constitucionais e cortes supremas como autoridade constitucional é um esperado efeito da consolidação de ideias como estado de direito e proteção a direitos fundamentais ao redor do mundo. ${ }^{7}$ Essa tese é particularmente frequente na defesa que os próprios juízes desses tribunais fazem da sua atuação. ${ }^{8} \mathrm{O}$ papel legitimador desse discurso é claro e significativo. Sua força crítica e o seu potencial explicativo, porém, são insuficientes. Quando reconhecemos o papel de variáveis políticas nesse processo, a impressão de que uma instituição com as características do Supremo pode fazer sozinha uma reviravolta institucional, sem que em algum momento sua atuação mais agressiva tenha sido modulada, validada e antecipada pelos outros dois poderes, mostra ser de fato apenas isto: uma impressão.

\footnotetext{
${ }^{4}$ Para um exemplo de trabalho nacional pioneiro nesta linha, ver o artigo de Cláudia Türner e Mariana Prado nesta edição da $R D A$.

${ }^{5}$ Ver, para o caso dos EUA, Whittington (2007).

${ }^{6} \mathrm{O}$ que não significa que não haja vozes dissonantes ou análises mais céticas em relação ao discurso dominante. Ver, por exemplo, neste número, os trabalhos de Manoel Gonçalves Ferreira Filho e Virgílio Afonso da Silva.

${ }^{7}$ Se essa descrição for verdadeira, como explicar então os casos de tribunais que tentaram proteger direitos fundamentais e empregaram esse mesmo vocabulário constitucional global - mas falharam, sendo enfim relegados a um segundo plano político ou até mesmo impedidos de funcionar, como ocorreu na Rússia nos anos 1990? Para alguns exemplos de variação de poder e o sucesso entre diferentes tribunais constitucionais, dos anos 1950 aos anos 1990, ver Ackerman (2007).

${ }^{8}$ Para citar apenas um exemplo entre muitos, confira-se a radical formulação de Aharon Barak, ex-presidente da Corte Suprema de Israel e um dos mais costumeiros defensores da supremacia judicial: "It is therefore no wonder that judicial review has become more common. The majority of enlightened democratic states have judicial review. It is difficult to imagine the United States, Canada, Germany, Japan, Spain, Italy, and many other nations without judicial review of constitutionality. The twentieth century is the century of judicial review. (...) It may be said that whoever argues that judicial review is undemocratic is in effect arguing that the constitution itself is undemocratic. To maintain that judicial review is undemocratic is to maintain that safeguarding human rights is undemocratic. To maintain that judicial review is undemocratic is to maintain that defending the rights of the individual against the majority is undemocratic" (decisão da Corte no caso United Mizrahi Bank v. Migdal Cooperative Village, HCJ 4804/94).
} 
O processo brasileiro, porém, também tem características que podem ser específicas, não necessariamente encontráveis nos estudos exemplares consolidados sobre a experiência de outros países. Por exemplo, o ativismo do STF parece ser jurisprudencialmente anunciado. Em alguns países, a expansão do poder judicial é produto de uma verdadeira reviravolta jurisprudencial ou de um conjunto de decisões imediatamente visível que rompe de forma abrupta com entendimentos antes considerados sólidos. Nesses casos, o tribunal anuncia publicamente: começa agora uma nova era. Esse anúncio representa uma transformação na forma como a separação de poderes e o próprio sistema jurídico são entendidos naquele determinado país - o que Stone Sweet (2007) batizou de coup d'état jurídico. Foi o caso da famosa decisão Lüth $^{9}$ do Tribunal Constitucional alemão, em 1958. Foi também o caso do julgamento de 1971 do Conselho Constitucional francês em que se começou a incorporar, no "bloco constitucional" do país, direitos fundamentais previstos no preâmbulo das constituições francesas anteriores e até mesmo na Declaração Universal dos Direitos do Homem e do Cidadão promulgada em 1789 - ainda que a inclusão de uma lista de direitos houvesse sido expressamente rejeitada na elaboração da Constituição da Quinta República. ${ }^{10}$

Não é o caso do Brasil. A expansão do poder do STF também é anunciada por decisões judiciais, mas não existe uma única decisão ou conjunto pequeno de decisões que possam ser pacificamente considerados o equivalente funcional de casos como Marbury vs. Madison, ${ }^{11}$ "mito fundador" do controle de constitucionalidade nos EUA, e Lüth, na Alemanha. Muito do que o Supremo faz hoje encontra respaldo no texto constitucional - e diversos ministros têm rebatido a crítica de "ativismo" apontando para as decisões positivadas da Assembleia Constituinte de 1987/88. Mesmo assim, o uso desses poderes tendeu a ser pavimentado aos poucos, com graduais, mas importantes correções de rumo na jurisprudência. Curtos e seguros passos para frente e, em certos casos, para trás. Mesmo quando existiram

\footnotetext{
${ }^{9}$ BFerfGE 7, 198 (1958). O Tribunal Constitucional articulou pela primeira vez neste caso a concepção - justificada por uma teoria da Constituição, e não pelo texto de dispositivos constitucionais específicos, como observa Stone Sweet - de que a Constituição expressa valores que permeiam todo o ordenamento jurídico. A consequência prática é a de que caberia a todo e qualquer juiz alemão zelar pela compatibilidade entre as leis e a Constituição - uma grande inovação em um país em que formalmente o Tribunal Constitucional tem o monopólio sobre o poder de declarar leis inconstitucionais.

${ }^{10}$ Decisão 71-44 do Conselho Constitucional francês, Recueil des Décisions du Conseil Constitutionnel 29 (1971). Citado em Sweet (2007).

${ }^{11}$ A decisão Marbury $v$. Madison (5 U.S. (1 Cranch) 137 (1803)) foi a primeira exposição sistemática da tese de que o poder da Suprema Corte dos EUA de controlar a constitucionalidade de leis aprovadas pelo Congresso Nacional - um poder não expressamente previsto no texto constitucional de 1787 - seria um corolário necessário da própria existência de uma Constituição escrita e rígida.
} 
importantes saltos jurisprudenciais - decisões afirmando poderes até então não completamente articulados,$-{ }^{12}$ as peças só foram realmente se encaixando aos poucos, em ritmos diferentes, em momentos diferentes. Se isso foi feito sem maior alarde de 1988 para cá, é porque os julgamentos do STF têm uma dupla face. O lado mais aparente é a solução adotada na decisão para a questão específica levada até o tribunal. Mas há mais. Em cada decisão, o Supremo também torna público o seu entendimento de qual é a extensão de seus poderes em relação ao Executivo e ao Legislativo. Na construção da motivação de suas decisões, tribunais hábeis podem expandir o seu poder no longo prazo, mesmo quando decidem favoravelmente ao Executivo ou ao Legislativo aqui e agora. Mesmo casos cujo resultado prático imediato é pouco relevante podem contribuir para revolucionar a estrutura da separação de poderes.

Toda decisão é uma oportunidade potencial de remarcar publicamente as fronteiras do poder judicial. Veja-se, por exemplo, a recente decisão do Supremo da reserva indígena Raposa Serra do Sol. ${ }^{13} \mathrm{O}$ caráter legislativo positivo da decisão foi claro, com explícita formulação de regras abstratas, prospectivas e gerais sobre demarcação. Política indigenista por meios judiciais; demarcação de terras indígenas com remarcação de fronteiras entre os poderes. Para entender como o STF usou essas oportunidades, mais do que pensar nas consequências positivas ou negativas das decisões de hoje, é preciso olhar para trás e refazer os seus passos jurisprudenciais.

\section{IV}

O que precisa ser decifrado, portanto, não é o fato em si da progressiva expansão de poder por parte das instituições judiciais. Afinal, este resultado reflete tendências globais e que estava ao menos em parte preparado pelo texto da Constituição de 1988. ${ }^{14}$ A questão mais interessante diz respeito ao momento da mudança de perfil do Supremo: Por que agora? Por que não antes — ou depois?

\footnotetext{
${ }^{12}$ Por exemplo, a ADIn 939/DF, julgada em 15 de dezembro de 1993, na qual o STF não apenas declarou inconstitucional uma emenda à Constituição, como também afirmou que os "direitos e garantias individuais" que constituem cláusulas pétreas (art. $60, \S 4^{\circ}$ ) estão espalhados pelo texto constitucional.

${ }^{13}$ Petição nº 3.388. As 19 regras tiveram significativa divulgação na imprensa - inclusive pelos meios institucionais do Supremo Tribunal Federal. Ver, por exemplo, a reportagem "STF impõe 19 condições para demarcação de terras indígenas", publicada em 19 de março de 2009, em Notícias do Supremo, disponível em <www.stf.jus.br/portal/cms/verNoticiaDetalhe.asp?idConteudo=105036\&caixaBusca=N> .

${ }^{14} \mathrm{O}$ caráter global do fenômeno é reconhecido mesmo por quem o vê como um problema. Ver, por exemplo, a posição do ministro Antonin Scalia, da Suprema Corte dos EUA, expressa na entrevista concedida a Caio Rodriguez e Marco Grandchamp, professores da FGV Direito Rio e reproduzida nesta edição. Por outro lado, Scalia parece acreditar que a expansão do poder judicial pode ser contida por meio de teorias normativas adequadas sobre qual é o dever do juiz (por exemplo, o originalismo).
} 
As respostas possíveis são múltiplas. Aqui, cabe apenas sugerir que algumas delas podem estar na combinação de um elemento sugerido pelos dois fatores mencionados até aqui: construção política e pavimentação jurisprudencial. Eles finalmente se cruzam no mais claro ponto de encontro institucionalizado entre mudança política e mudança de jurisprudência: o processo de indicação conjunta, para novos ministros do STF, por parte do presidente e do Senado. ${ }^{15}$ De 2003 para cá, praticamente $2 / 3$ da composição do tribunal foi renovada pelo presidente Lula. Na mesma época, aposentaram-se os últimos três ministros indicados antes de 1988, quando as expectativas em relação ao cargo - por parte tanto de quem os indicou, quanto da sociedade - eram muito diferentes. É arriscado querer explicar o tempo da mudança de orientação do STF sem ao menos tentar integrar essa variável na análise.

Esses são elementos de uma agenda de pesquisa - perguntas, mais do que respostas. Pontos de partida. O que há de único na construção política do protagonismo do STF? O que há de comparável a outros países no seu uso da jurisprudência? Em que medida experiências e modelos teóricos desenvolvidos em outros países podem nos ajudar na compreensão do momento judicial pelo qual passamos? São problemas à procura de análises - e análises em busca de informação.

\section{Referências}

ACKERMAN, Bruce. A ascensão do constitucionalismo mundial. In: SARMENTO, Daniel; SOUZA NETO, Claudio Pereira de. A constitucionalização do direito: fundamentos teóricos e aplicações específicas. Rio de Janeiro: Lumen Juris, 2007.

DAHL, Robert. Decision-making in a democracy: the Supreme Court as a national policy-maker. Journal of Public Law, n. 6, p. 279, 1957.

EPSTEIN, Lee; KNIGHT, Jack. The choices judges make. Washington, DC: Congressional Quarterly Press, 1997.

HIRSCHL, Ran. Towards juristocracy: the origins and consequences of the new constitutionalism. Cambridge, MA: Harvard University Press, 2004.

GINSBURG, Tom. Judicial review in new democracies: constitutional courts in Asian cases. New York: Cambridge University Press, 2003.

SWEET, Alec Stone. Governing with judges: constitutional politics in Europe. Oxford: Oxford University Press, 2000.

\footnotetext{
${ }^{15}$ Como sugerido no seminal artigo de Robert Dahl (1957:279).
} 
. Juridical coup d'état and the problem of authority. German Law Journal, v. 8, n. 10, 2007.

VIANNA, Luis Werneck; CARVALHO, Maria Alice Rezende de; CUNHA, Manuel Palacios da; BURGOS, Marcelo Baumann. Judicialização da política e das relações sociais no Brasil. Rio de Janeiro: Revan, 1999.

VIEIRA, Oscar Vilhena. Supremocracia. Revista Direito GV, São Paulo, v. 4, n. 2, p. 441-464, jul./dez. 2008.

WHITTINGTON, Keith. Political foundations of judicial supremacy. Princeton: Princeton University Press, 2007. 